is reversible, in contrast to releasing chemicals that may have undesirable side effects.

In his large ( 3.7 cubic meters) atmospheric chamber at UCLA, Wong created a healthy stratosphere complete with ozone and ultraviolet light. He then injected a minuscule amount of CFC, until nearly all of the ozone was depleted. Then, by charging the model atmosphere with the form of an electrical current generated by a radio frequency transmitter, he disabled the $\mathrm{CFC}$, and the ozone level in the atmosphere returned to normal.

The UCLA physicist has begun testing his idea outside the lab, using helium balloons to lift to the stratosphere a solar-powered platform carrying a large electrical "curtain." Chlorine atoms will be neutralized as they pass through the curtain, gaining an electron.

Wong envisions up to 20 platforms deployed at the North and South poles, which could reduce the ozone hole by $50 \%$ in as little as 5 years. Each platform would cost $\$ 25$ million, but their cost could be offset, for instance, by using them to carry telecommunications and astronomy equipment as well. The platforms would be brought down every 2 to 4 years for maintenance, then reused.

\title{
Research
}

update

\section{Researchers try to arrest fugitive dust}

$\mathrm{B}$ rown haze, the signature of polluted air, is only the most visible part of the problem. Consider ozone, the invisible toxic gas formed when nitrogen oxides and hydrocarbons react with sunlight, and particulate matter 10 microns $(1 / 7$ the diameter of the average human hair) or less in diameter (PM-10). Both cause health problems and reduce agricultural crop yields.

University of California scientists have previously demonstrated that ozone causes annual losses as high as $20 \%$ in some San Joaquin Valley crops. In current research, they are learning how agriculture both contributes to and mitigates air pollution. Extension air quality specialist David Grantz has found that farm crops remove large amounts of ozone from the air, which may significantly benefit air quality (see page 9).

Other scientists are determining how and to what degree agricultural practices contribute PM-10 dust to the air. PM-10 dust is a health concern because it can bypass the body's natural defense mechanisms and settle permanently in the lungs. (Inhaled dust particles larger than 10 microns in diameter can be expelled.) Once PM-10 settles in the lungs, it can increase asthma attacks, reduce lung function, aggravate bronchitis, result in respiratory disease and lead to premature death, according to Karlyn Black, statewide PM-10 specialist for the California Air Resources Board. PM-10's effects are most apparent in elderly people, children, chronic heart disease patients, chronic respiratory disease patients and people with asthma, but ultimately it affects everyone.

Research defining how best to reduce PM10 is urgently needed. Currently only Lake County meets state PM10 standards. Under the federal Clean Air Act, areas not designated as nonattainment

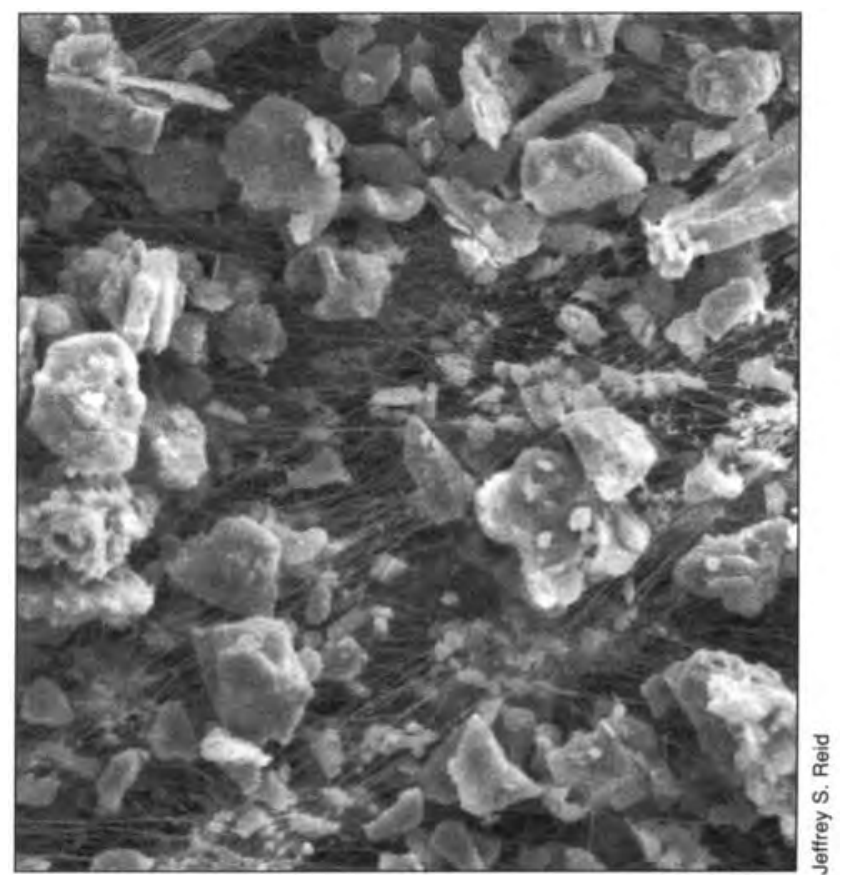

Particulate matter 10 microns or smaller, PM10 , is a health concern because it can settle in the lungs, impairing respiratory functions. 


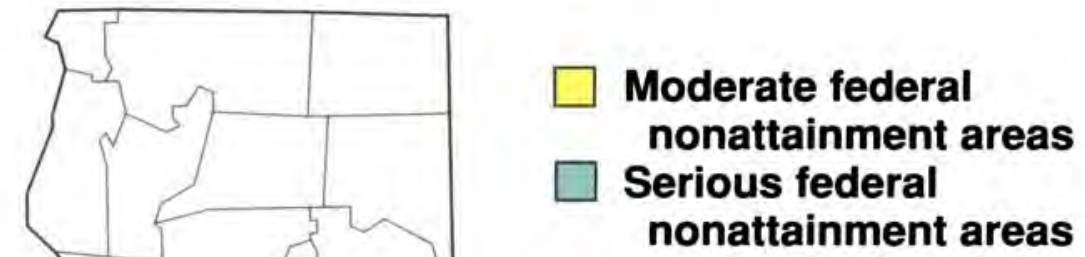

Ten areas in California exceed federal PM-10 standards Of these, six "moderate" areas must implement control measures now and show attainment by dates ranging from $\mathrm{De}$ cember 1994 to December 2000. Four "serious" areas must implement controls by February 8,1997 , and show attainment by December 2001. Only Lake County meets the state's stringent PM-10 standards. Map courtesy of Karlyn Black.

are considered "unclassified" by EPA, which continues to monitor them for violations of daily and/or annual standards. While there is currently no legislation to enforce state stan-

Gravity pulls down the larger sizes, but a particle less than 1 micron in diameter can be carried hundreds of miles. dards, federally-designated "serious nonattainment areas" (see map above) must submit PM-10 reduction plans by August 8 , 1994 to be implemented by February 8, 1997. Federal standards must be met by December 31, 2001.

The federal standard for PM-10 is a maximum of 150 micrograms per cubic meter of air over any 24-hour period and a daily average of no more than 50 micrograms per cubic meter over a year period. State regulations limit PM10 emissions to no more than 50 micrograms per cubic meter within any 24 -hour period and a daily average of no more than 30 micrograms per cubic meter over a year's time. Everyone will be able to breathe easier once these standards are met, but first the major sources of rural PM-10 must be identified.
The primary suspects are paved and unpaved roads, construction and demolition operations, blowing soil, agricultural operations and burning. Other PM-10 sources are tail pipe emissions, combustion products, industrial sources and animal waste.

Little data exists on actual California dust emissions. Data on contributing sources, constituents of PM-10 dust and how far it can be transported are just now being gathered. These factors and their effects could be quite different for urban and rural PM-10. Urban PM-10 is likely to contain smaller, more toxic substances from industrial sources. Rural PM-10 is more likely to contain soil particles, which are larger, according to Robert Flocchini, professor of atmospheric science, UC Davis. Gravity pulls down the larger sizes, but a particle less than 1 micron in diameter can be carried hundreds of miles.

When the Environmental Protection Agency declared the San Joaquin Valley a serious nonattainment area, "people thought agriculture must be a primary cause; however, there was no supporting data," said Flocchini, who has begun doing the necessary research.

In 1990, Manuel Cunha of the Nisei Farmers League in Fresno and other industry members were surprised to learn that EPA's dust estimations were based on some inaccurate assumptions. One flawed assumption, Cunha said, was that alfalfa - a perennial crop that is mowed for about 5 years before the field is tilled and replanted - is tilled eight times a year.

"Also, we have 2,400 soil types in California and past EPA research had indicated that California soils were predominantly a white ash alkali," he said.

Proposed control measures had not been tested and no economic analysis of the measures had been done, Cunha said. However, Barbara Bates, environmental scientist and EPA western regional PM-10 coordinator, described the list as suggested control measures offered as a starting point. She noted that EPA has provided the SJV Unified Air District \$2.4 million so far for additional research to develop better emission estimates.

Cunha, along with members of state agencies and other industries, including construction, oil and gravel, formed an advisory group to determine what data were needed to create a workable plan to reduce fugitive dust, which contains PM-10. Working with representatives of local, state and federal agencies, the group has been securing funds for several air quality re- 


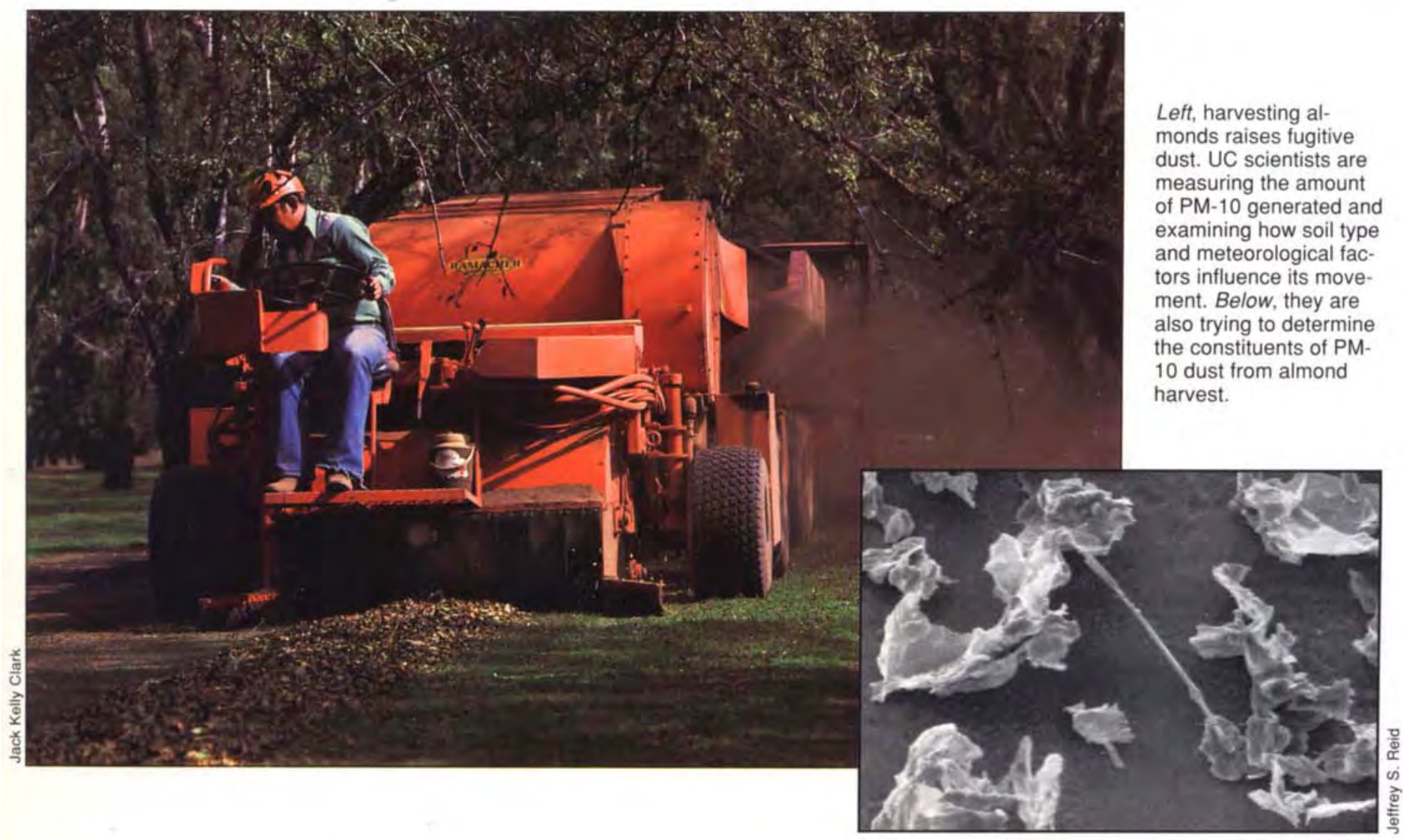

search projects, parts of a proposed $\$ 23.5$ million, 8-year study. To date, $\$ 6.2$ million in private and government grants has been collected.

Flocchini conducted a 3-year study, ending in 1993, to measure dust generated by agricultural activities and unpaved roads. Cotton harvest and almond harvest were chosen because they were thought to raise a lot of dust and cover large acreages. California grows about 400,000 acres of almonds and over 1 million acres of cotton. Overall, Flocchini's PM-10 emission results were $66 \%$ less than EPA models suggested, but land preparation results were closer, 39\% lower than EPA calculations. However, Flocchini cautioned against assigning his data to other areas of the state because the study was small in scale. His findings won't affect regulations, but will help steer industry toward effective PM-10 control plans.

His current 5-year study takes a broader approach. He is looking at different soils, different meteorological factors and the agricultural operations themselves. "We must account for more atmospheric conditions to accurately describe particle transport," he explained. During the summer, surface ground heating can cause great atmospheric turbulence, lifting dust particles high into the air. On the other hand, low level inversions and night time conditions limit the initial injection height of PM-10 dust particles into the atmosphere. Both limit particle dispersion and can cause high levels of PM-10 near the ground surface, where it is more likely to resettle.

For the last year, Mike Singer, soil scientist at UC Davis, has been measuring the amount of dust produced by different farming practices, specifically dust particles smaller than $3.5 \mathrm{mi}$ crons (the size their equipment was designed to trap). Singer collected air samples from the breathing space of tractor drivers and from outside the equipment. Singer and UC Davis soil scientist Randy Southard are also comparing the composition and amount of dust generated by organic versus conventional farming systems. Singer said they might find pesticide residues in dust from conventionally farmed areas and different organic compounds in dust from organic plots. "The composition of dust is a big bag of unknowns," Southard said.

UC industrial hygienist Bob Lawson, of the Agriculture Health and Safety Center in Davis, 


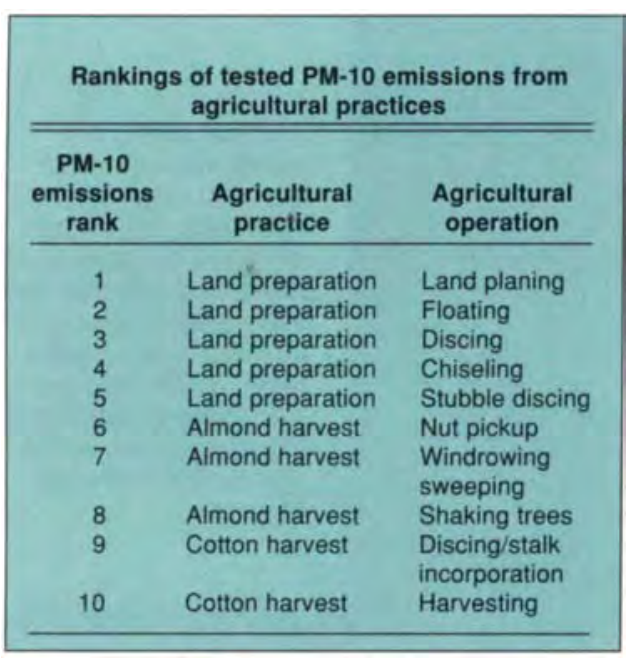

is working with Singer and Southard to measure occupational exposure. While silica is known to harm the lungs, Lawson would like to find out what other PM-10 constituents cause health problems. "There's very little documentation of exposure effects," he said.

This is an important part of PM-10 research, in the opinion of Flocchini, because each sample can have a different set of constituents. "Because PM-10 includes all particles with aerodynamic size of 10 microns or less," he explained, "it will be different in Los Angeles compared to Sacramento, and different again in Parlier."

In addition to the quantity and quality of the dust, researchers are trying to discern what conditions produce more dust. "An important variable is soil moisture," Singer said, "When soil moisture is high, there's not much dust."

Southard is also tracking how far dust is

Because PM-10 includes all particles with aerodynamic size of $10 \mathrm{mi}-$ crons or less, it will be different in Los Angeles compared to Sacramento... transported and what influences how far it travels. By monitoring an array of sampling stations set up throughout the Central Valley, researchers will be able to tell whether dust raised in Davis settles in the field or rides the breeze to Bakersfield.

UC Davis agricultural engineer Henry Studer has been testing an almond harvester modified to shake out dust as it picks up the windrowed almonds. Although the procedure seemed to raise less dust, Studer said he's not sure whether it reduced the amount of PM-10. "We used a longer separating section with a little vibration to try to remove the dirt with gravity from the leaves and nuts and twigs before it got to the fans," Studer said. "I think we'll find the heavy stuff is what drops out." The data is being evaluated.

The goal of all these projects, Flocchini said, "is to develop an inventory of PM-10 emission from practices under various conditions to help industry make appropriate and economically viable changes."

Land preparation topped the list of 10 agricultural practices examined in Flocchini's study giving off the most fugitive dust (see box).

Reducing tillage on fallow land is one way of keeping dust down, but growers turn the soil to prevent weeds from taking over and endangered species' habitats from developing, according to Roger Isom, director of technical services for the California Cotton Growers Association and California Cotton Ginners Association, based in Fresno. If an endangered species moves in, it effectively removes that land from production. Two farms, in Kern and Tulare counties, were heavily fined and the Kern County farm's tractor confiscated after dead kangaroo rats and blunt-nosed leopard lizards were found in fallow fields the growers had plowed. "Because an endangered species moved in, it constituted 'taking' of an endangered species," Isom said.

Nonagricultural activities contribute dust as well.

In earlier work done for the Air Resources Board, Tom Cahill, professor of physics and atmospheric sciences and head of Air Quality Group at UC Davis, was commissioned to estimate the amount of fugitive dust coming off California highways.

Cahill collected air samples from freely running and congested freeways, then calculated the amount of dust emitted per vehicle mile traveled. The dust collected from the highways was considerably lower than that of the EPA estimates by factors of 3 to more than 10 .

"We feel that the dust coming off California paved roadways may not be well represented by estimated emission factors from EPA," Cahill said. "We're doing a study to identify what we hope are more realistic emission factors from paved roadways. We do direct mass balance studies comparing upwind and downwind concentrations on real highways."

In a new study for Caltrans, he plans to analyze the components of the dust coming off freely running and congested freeways and heavily traveled four-lane roads, then trace their sources, tires, asphalt, etc. - Editor

CAL AG on Internet: Major sections of California Agriculture are now available on the Internet Gopher system. Editorials, tables of contents, news sections, and manuscript abstracts from the last three issues can be called onto your computer screen.

Once you've accessed the Gopher system, select "University of California Systemwide Administration" or "UC Office of the President" (depending on which appears as an option), then "UC Systemwide Information Services," then "UC Division of Agriculture and Natural Resources News and Publications" and finally "California Agriculture journal." 